\title{
Correction to: The effects of microdose LSD on time perception: a randomised, double-blind, placebo-controlled trial
}

\author{
Steliana Yanakieva ${ }^{1} \cdot$ Naya Polychroni $^{1} \cdot$ Neiloufar Family $^{2} \cdot$ Luke T. J. Williams $^{2,3} \cdot$ David P. Luke $^{4} \cdot$ Devin B. Terhune $^{1,5}$ \\ Published online: 22 October 2020 \\ (C) Springer-Verlag GmbH Germany, part of Springer Nature 2020
}

\section{Correction to: Psychopharmacology \\ https://doi.org/10.1007/s00213-018-5119-x}

\section{The original version of this article included the following} paragraph (p. 1161), which was incorrect:

"The manufacturer of the drug product was Onyx Scientific Limited UK, to cGMP standards. Onyx Scientific Limited UK also undertook the pharmaceutical form development work to establish the optimal process for the manufacturer of the three doses of LSD. The doses were made by the pharmacy at the clinical trial facility under their manufacturing licence conditions and following the process outlined in the IMPD. A manual containing detailed instructions for the storage, manufacture of the doses, dispensing, and reconciliation was followed and worksheets were monitored by an independent clinical research associate during the study. LSD tartrate was prepared as a solution in distilled water. Placebo was distilled water only (indistinguishable from the LSD solution). Stability testing was done for a 6-month period."

The online version of the original article can be found at https://doi.org/ 10.1007/s00213-018-5119-x

Devin B. Terhune

d.terhune@gold.ac.uk

1 Department of Psychology, Goldsmiths, University of London, 8 Lewisham Way, New Cross, London SE14 6NW, UK

2 Eleusis Pharmaceuticals Ltd, London, UK

3 Centre for Psychiatry, Division of Brain Sciences, Imperial College London, London, UK

4 Department of Psychology, Social Work, \& Counselling, University of Greenwich, London, UK

5 Department of Experimental Psychology, University of Oxford, Oxford, UK
The correct paragraph is presented here:

"The manufacturer of the drug product was Onyx Scientific Limited UK, to cGMP standards. The doses were made by the pharmacy at the clinical trial facility under their manufacturing licence conditions and following the process outlined in the Investigational Medicinal Product Dossier (IMPD). A manual containing detailed instructions for the storage, manufacture of the doses, dispensing, and reconciliation was followed and worksheets were monitored by an independent clinical research associate during the study. D-Lysergic acid diethylamide (D-LSD, HPLC purity $>99 \%$ ) was dissolved in ethanol at $25 \mathrm{mg} / \mathrm{mL}$ and prepared as a solution $50 \mu \mathrm{g}$ or $2 \mu \mathrm{g}$ $\mathrm{D}-\mathrm{LSD} / \mathrm{mL}$ in distilled water and completed to a final volume of $10 \mathrm{~mL}$ distilled water for oral administration. A shelf life of 78 hours was allocated to the doses, when stored in the defined container closure at a temperature of $2-8{ }^{\circ} \mathrm{C}$, with the start of the expiry period being defined as the time of combining the D-LSD with ethanol. Placebo was distilled water only (indistinguishable from the LSD solution)."

Publisher's note Springer Nature remains neutral with regard to jurisdictional claims in published maps and institutional affiliations. 